\title{
Assessment of Infection Control in Dental Clinics at Ibb City, Republic of Yemen: Dentists' Perspective
}

\author{
Ahmed Mohammed Alduais ${ }^{1, ~ *, ~ S a l a h ~ G h a l i b ~ M o g a l i ~}{ }^{2}$ \\ ${ }^{1}$ Department of Linguistics, Institute of Social Sciences, Ankara University, Sihhiye, Ankara, Turkey \\ ${ }^{2}$ Department of Health Administration, College of Business Administration, King Saud University, Riyadh, Kingdom of Saudi Arabia
}

Email address:

amsalduais@gmail.com (A. M. Alduais), salah_mogly@yahoo.com (S. G. Mogali)

\section{To cite this article:}

Ahmed Mohammed Alduais, Salah Ghalib Mogali. Assessment of Infection Control in Dental Clinics at Ibb City, Republic of Yemen: Dentists' Perspective. Science Journal of Public Health. Vol. 3, No. 3, 2015, pp. 423-432. doi: 10.11648/j.sjph.20150303.29

\begin{abstract}
Purpose: The aim of this study was to find out the practical infection control procedures from the dentists' perceptive at hospitals and dental centers at Ibb city in the Republic of Yemen. Method: The data was drawn using a researcher-made questionnaire, random sampling procedures was followed to select 252 dentists from the private, governmental, teaching hospitals and from dental centers at Ibb city in the Republic of Yemen, using a descriptive analysis. Results: The researchers found that the participating dentists agree to the weakness role of the administration regarding infection control where they varied in responding to the role of the dentists during the preparation stage and post treatment stage, but agreed to the treatment phase practices. There was a shortage in practical dealing with the medical waste management and clear shortage in the qualification and training among the nursing staff according to the collected data. The biggest problem with the reviewers who have infectious diseases and didn't reveal their health status to the dentists with percentage $62.7 \%$ dissatisfied the current infection control management, also dissatisfied the role administration of the hospital and the Ministry of the Health. Conclusion: These findings are the first to document the practical infection control and the role of administration in Yemen. The situation is very critical and an action needs to be taken by decision-makers and health organizations.
\end{abstract}

Keywords: Infection Control, Health Administration, Medical Waste, Nursing Staff, Patient Safety, Dentist Role

\section{Introduction}

The emergence of life-threatening infectious diseases demands the implementation of efficient infection control practices in health care facilities. Failure to adhere to infection control measures leads to the spread of pathogens and microorganisms which influences the health of both the healthcare personnel (staff) and the community in general [11]. Several professional health agencies such as the Centers for Disease Control and Prevention (CDC), Occupational Safety and Health Administration (OSHA), American Dental Association (ADA) in the United States and National Institute of Health and Clinical Excellence (NICE) in the United Kingdom, have issued specific recommendations attempting to minimize the risk of cross infection during dental practices. These guidelines suggest routine use of gloves, masks, goggles, and sterilization of dental instruments, vaccination against $\mathrm{HBV}$, and the universal (standard) precautions [13]. Dental treatments are considered as one of the most important risk factor for HBV infection [14].

Today the work related infection spread is very common in developing countries, including Yemen. Dental treatment procedures along with the other health procedures involve contact with blood, human secretions and oral tissues which carry risk of contamination with the infectious microorganism like human immunodeficiency viruses (HIV) and hepatitis B viruses (HBV). By this means, all the dentists and the assistant nursing staff working in the dental clinics must be familiar with infection control procedures to control infections and reduce the transmission of the disease [25]. The environment in dental practices and clinics is far from being perfect and ideal.

A Fifth of infectious diseases may be transmitted in the dental clinics either via direct contact with saliva, blood or oral secretions or via indirect contact with contaminated 
equipment and instruments or contact with aerosolization of blood and saliva from the patients mouth [25]. Implementation of infection control practices is influenced by different dentists and factors related to practice.

Lack of concern regarding potential personal risk, costs of infection control practices, limited access to required tools and materials, and practicing in public clinics have been indicated as barriers to comply with infection control practices among dentists. Because not all patients with infectious diseases can be identified through routine physical examination or laboratory tests, the patients may be without any signs or symptoms (asymptomatic), so the high standard precaution must be taken and followed for all patients coming to dental clinics and must be provided with a high protection for all the health staff working in the dental clinics [25]. Having said that different roles in relation to this topic have to be accounted for.

Firstly, the role of the administrators in the dental infection control where most of the countries have clinical practice guidelines (evidence-based recommendations) which are set forth by regulatory and advisory agencies to promote safety in the implementation of patient care. In 2003, the Centers for Disease Control (CDC) developed and issued the Guidelines for Infection Control in Dental Clinics. These guidelines aid in infection control [17]. [27] showed the role of hospital administrative in four areas: 1) educating staff regarding the patient safety culture: we must show our team our commitment to a culture of patient safety, explain its importance, and act as a team, 2) we must understand the current situation before taking any measures, and we can also review our protocols for action in a lifethreatening issue, 3 ) devise protocols to make activities less dangerous, and 4) establish safety instructions: these represent the 'red lines' over which we should not step in everyday practice.

A study presented the role of the administrative in encouraging patients to participate in the decision-making process of dental care and improving the effectiveness of communication among all dental providers [12]. Another study demonstrated the role of the administration in improving open communication with the dental staff, feedback and communication about errors following adverse events reporting, management support for the patient safety programs, non-punitive response errors, team work across the hospitals and the dental clinics and the supervision and actions promoting patient safety [2].

One more study also focused on the importance of feedback communication, team work cross the units, nonpunitive response to errors, supervision and promoting patients' safety [1]. CDC guidelines specify that infection control practices are to be applied in all settings where dental treatment is provided. However, participants indicated that the guidelines were hard to apply and that infection control guidelines for settings using portable equipment would be useful.

Secondly, the role of the dentist before, during and after treatment, [15] and [25] in Canada found that most dentists comply with the use of gloves, masks, eyewear protective and immunization against HBV for themselves; however, many dentists do not follow and utilize the full range of recommended infection control procedures that are necessary to minimize the risk of cross-infection in dental practice.

Vázquez et al. found that dentists have a good perception that infection control prevents the transmission of blood borne viruses [23]. Cleveland et al. indicated that the implementation of four recommendations (dental unit water quality and separate dental unit waterline system, referring and documenting percutaneous injuries, trying or using safer syringes and safer scalpels and factors associated with implementing infection control recommendations varied among dentists in the U.S) [8]. Strategies aimed at raising awareness of the importance of infection control in dental clinics. Increasing continuing education programs and developing multiple modes of instruction may increase implementation of current and future dental Centers for Disease Control and Prevention guidelines [8].

Szymańska et al. found that in daily dentists' practices, dentists do not follow procedures, leading to increase of microbiological contamination of dental unit reservoir water [22]. They are unaware of the principles of dealing with dental water and water supply systems or the health risk posed by microbiological contamination of unit water for the dental team and patients.

Vega et al. indicated that there is a lack of knowledge among dentists regarding proper hand hygiene [24]. Budnyak et al. showed disparity in the practice of infection control and safety procedures requiring formulation of nationwide dental safety standards [7]. Khan et al. pointed out that the knowledge of dental practitioners in the region was good and there was increased awareness as far as sterilization and cross infection was concerned, but when it comes to practice [13].

Osazuwa et al. mentioned that there were gender differences in age and professional categories among workers in oral health. However there appears to be no gender differences in terms of general infection control procedures, except for three infection control measures: hand hygiene (favored by women), eye protection (preferred by women) and protective clothing (favored by men) [18].

The study of Batool et al. indicates that there were deficiencies in the knowledge, attitude and practices about hepatitis $\mathrm{B} \& \mathrm{C}$ virus in dentists of both public and private sector, such as not being vaccinated for hepatitis B and infrequent use of special containers to dispose sharps [6]. Deficiencies are more marked in private sector included infrequent hand washing, not using autoclave for sterilization, not using new forceps/hand piece or personal protective equipment's (mask/eye face shield) [6]. Wijk et al. stated that there were nationwide data that showed blood exposure incidents occurring frequently in dental clinics [26].

Thirdly, the role of medical staff assistant in the dental 
infection control, Garland et al. found that the dental hygienists are adhering with most aspects of the infection control guidelines (ICG) [10]. High compliance with ICG (infection control guidelines) among respondents in this study was associated with positive safety practices and beliefs, whereas lower compliance with ICG was associated with less positive safety beliefs and practices [10].

Weheida et al. found that most of the hygienists followed the infection control precaution in some procedures like: wearing the gloves and changing the gloves after each patient, also the hand cleaning, but there are other aspects that remain problematic such as: immunization against hepatitis B and post immunization tests. Wearing masks and eyewear were very poor among the dentists and dental hygienists [25]. Francisco et al. pointed out that there is a need to improve practicing dental hygienists' knowledge and involvement in the infection control practices [9].

Fourthly, the degree of medical waste management, Singh et al. stated that a total of $494(70.6 \%)$ dentists responded to study, general dentists reported using boiling water as a sterilizing medium and $(68.6 \%)$ dentists reported disposing of hazardous waste such as syringes, ampoules and blades in dustbins and emptying these into municipal corporation bins [20].

Nabizadeh et al. found that the total annual amount of dental waste produced in public and private dental practices in Gorgan was 12015.1 and $3135.0 \mathrm{~kg}$, respectively. The dental waste management in Gorgan is inadequate; dental waste is not actually segregated, collected, and disposed, as demanded by WHO [16].

Bansal et al. found that about $26 \%$ of dentists practiced wrong measures to dispose sharps and extracted tooth, respectively. $32 \%$ of dentists did not dispose outdated and expired medicines rightly [3]. The researchers concluded that the majority of dental practitioners were aware of categories and color coding used for disposal of different types of wastes, yet they did not follow the same in their practice [3].

Rudraswamy et al. found that $82.6 \%$ of attenders said that it is necessary to segregate waste into different categories at the point of origin, $61.5 \%$ of auxiliaries strongly disagreed that segregation of waste at source increases the risk of injury to waste handlers [19]. As many as $33.5 \%$ of dentists strongly disagreed that segregation of waste at source increases the risk of injury to waste handlers and $53.6 \%$ agreed that segregation of waste at source does not increase the risk of injury to waste handlers [19].

Finally, the role of patients, Barghout et al. in Jordan found that $83.5 \%$ of patients reported necessity for the dentist to wear gloves. Another about three-quarters $(74.8 \%)$ found it necessary for the dentist to wear a mask [4]. The majority $(76.8 \%)$ stated the method of HIV transmission was by dentists using needles previously used for patients infected with AIDS; 71\% knew there is no vaccine against HIV. Only half (49\%) reported that hepatitis could be transmitted by blood transfusion. About 53.5\% claimed their knowledge regarding infection transmission was obtained through watching television programs about cross infection [4].

Baseer found that less than $50 \%$ dental patients were aware of the spread of infection in dental clinics via saliva, blood and unsterilized contaminated dental instruments [5]. Over $90 \%$ said that dentists should wear gloves, and face masks. Seventy five percent study participants would like their dentist to change the gloves after every patient. $82.7 \%$ of the patients agreed that dentist must wear gloves, mask and spectacles, while providing treatment. $77.7 \%$ refused to attend clinics if they knew that AIDS and Hepatitis-B patients are treated there. The researcher concluded that the patients revealed adequate knowledge towards the use of gloves, mask and spectacles by dentist. However, the patients' knowledge regarding the spread of Hepatitis-B, HIV infection was poor [5]. Smith et al. pointed out that majority concerns of patients revolved around hand hygiene practices rather than risks from HBV [21]. On the basis of the above presentation, the current study raises the following questions for the case of Yemen in Ibb city:

1. What is the role of administrators in dental infection control?;

2. What is the role of dentists before, during and after treatment?;

3. What is the role of medical staff assistant in the dental infection control?;

4. What is the degree of the medical waste management?;

5. What is the role of patient in the dental infection control?; and

6. What is the level of the dentist satisfaction regarding infection control in general?

\section{Methods}

\subsection{Population}

The study population consisted of dentists working in the private, governmental, teaching hospitals and in the dental centers at Ibb city in the Republic of Yemen.

\subsection{Sampling}

The sample covered 252 dentists using simple random sampling. This number was considered as a representing number for the purposed of our study.

\subsection{Measures}

\subsubsection{Questionnaire}

Survey instrument used in this study was a questionnaire which was developed by the researchers. It consisted of 7 sections as it follows:

1. Section 1: socio-demographic information;

2. Section 2: information regarding the role of administrators in the dental infection control;

3. Section 3: information regarding practical role of the dentist before, during and after treatment;

4. Section 4: information regarding the role of the medical 
staff assistant in the dental infection control;

5. Section 5: information regarding the degree of the medical waste management;

6. Section 6: information regarding the role of patient in dental infection control; and

7. Section 7: information regarding the level of dentist satisfaction regarding infection control in general.

\subsubsection{Instrument Validity and Reliability}

To assure the validity of questionnaire, the following procedures were conducted. Firstly a review was made of the relevant literature (see introductory section) and the previous instruments were examined to develop drafts. Secondly, the questionnaire was given to three professors of health care administration to judge it. Reliability was measured by using the Cronbach alpha tool- based on 54 items in the survey, a score 0.903 was obtained which means higher reliability of items.

\subsection{Research Design}

The current study followed a survey-study approach and. It attempted to reach a certain description of the level of the problems which can be explored and investigated further using another and/or other research design.

\subsection{Procedure}

The data was collected by one of the researchers while the assistants explained the tools used in the study prior to collecting sample data though questionnaires. After that, desirable questionnaires were distributed directly to all participants in the area .The data was collected during the period from $1 / 4 / 2013$ to $30 / 8 / 2013$. An average 6 minutes was required to complete the instrument. Nearly 270 copies of the questionnaire were distributed with 10 copies of the questionnaire not returned. Besides, from 260 forms, there were 8 incomplete. Forms a total of 252 of 270 (93.3\%) questionnaire forms were returned, giving response rate of $93.3 \%$.

\subsection{Variables}

Infection control: infection prevention and control measures aim to ensure the protection of those who might be vulnerable to acquire an infection both in the general community and while receiving care due to health problems, in a range of settings. The basic principle of infection prevention and control is hygiene (WHO).

Patient safety: is defined by the Institute of Medicine (IOM) as the freedom from accidental injury due to medical care or medical errors [27].

\section{Results}

The data was analyzed using SPSS version 20. The aim of this study was to find out the practical infection control procedures from the dentists' perceptions at hospitals and dental centers at Ibb city in the Republic of Yemen. Answers for the raised questions in the introductory section are presented below. To remind ourselves of the raised questions; they were:

1. What is the role of administrators in dental infection control?;

2. What is the role of dentists before, during and after treatment?;

3. What is the role of medical staff assistant in the dental infection control?;

4. What is the degree of the medical waste management?;

5. What is the role of patient in the dental infection control?; and

6. What is the level of the dentist satisfaction regarding infection control in general?

Table 1. Socio-demographic information.

\begin{tabular}{|c|c|c|c|}
\hline & Variables level & Frequency & $\%$ \\
\hline \multirow{3}{*}{ Gender } & Male & 132 & 52.4 \\
\hline & Female & 120 & 47.6 \\
\hline & Total & 252 & 100.0 \\
\hline \multirow{5}{*}{ Position } & Governmental hospital & 78 & 31.0 \\
\hline & Dental centers & 63 & 25.0 \\
\hline & Private hospitals & 57 & 22.6 \\
\hline & Teaching hospitals & 54 & 21.4 \\
\hline & Total & 252 & 100.0 \\
\hline \multirow{4}{*}{ Age } & 20-30 years & 169 & 67.1 \\
\hline & $31-40$ years & 74 & 29.4 \\
\hline & 41 and above & 9 & 3.6 \\
\hline & Total & 252 & 100.0 \\
\hline \multirow{5}{*}{ Experience } & $0-5$ years & 161 & 63.9 \\
\hline & $6-10$ years & 64 & 25.4 \\
\hline & 11-15 years & 24 & 9.5 \\
\hline & 16 years and above & 3 & 1.2 \\
\hline & Total & 252 & 100.0 \\
\hline
\end{tabular}

It can be clearly seen from table (1) that most of the participants were from male representing $52.4 \%$ then female with $47.6 \%$. It can be noticed that most of the participants were from governmental hospital representing $31 \%$, followed by dental centers representing $25 \%$, and then private hospitals representing $22.6 \%$ with teaching hospital as the last rank representing only $21.4 \%$. In regard to age of the participants, most of the participants' age ranges from 20-30 years, representing $67.1 \%$, followed by $31-40$ years representing $29.4 \%$ and then 4lyears and above, representing $3.6 \%$. Most of the participants experience varied from $0-5$ years representing $63.9 \%$, 6-10 years representing $25.4 \%, 11-15$ years represent $9.5 \%$, and then above the 16 years represent $1.2 \%$. It should be noted that all the dentists are holders of a bachelor degree in dentistry sciences. 
Table 2. The Role of the administrators in infection control.

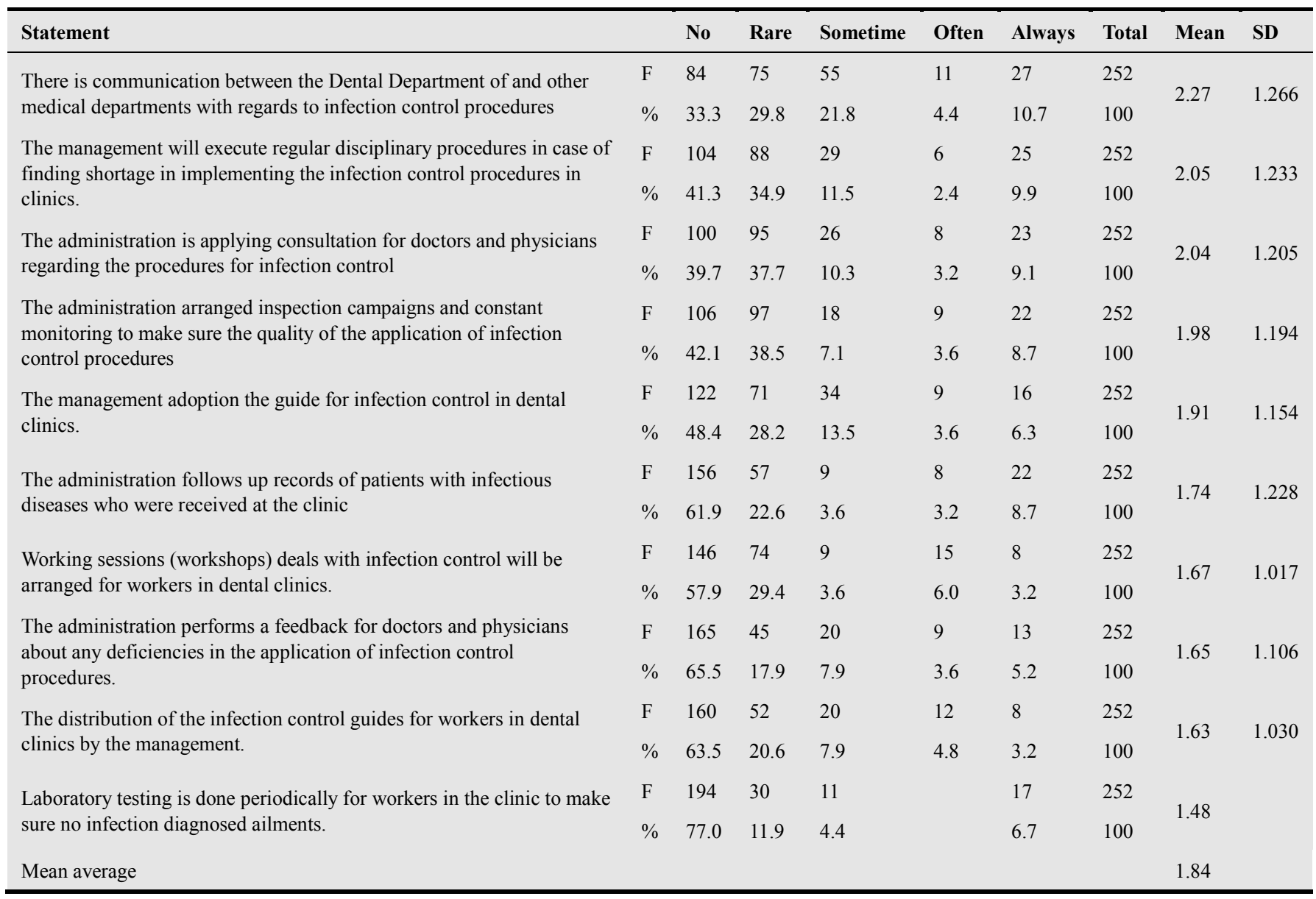

We can see from table (2) that the participants varied in response to the role of the administration in dental infection control with the mean range from $\mu=2.27$ to $\mu=1.48$. The highest mean range was for item 1 (there is a communication between the Dental Department and other medical departments in regard to infection control procedures). On the other hand, the lowest mean was for the last item (laboratory testing is done periodically for workers in the clinic to make sure no infection diagnosed ailments).

Table 3. dentists 'treatment of infected patient.

\begin{tabular}{lllll}
\hline Statement & Frequency & Percent & Valid Percent & Cumulative Percent \\
\hline Has never encountered such case & 14 & 5.6 & 5.6 & 5.6 \\
Refuse treatment & 18 & 7.1 & 7.1 & 12.7 \\
Treated in the clinic with the acceptable minimum level of prevention & 43 & 17.1 & 17.1 & 29.8 \\
Transfer him to clinic specialist for these cases & 37 & 14.7 & 14.7 & 44.4 \\
Treatment in the clinic with maximum high level of protection & 140 & 55.6 & 55.6 & 100.0 \\
Total & 252 & 100.0 & 100.0 & \\
\hline
\end{tabular}

We can see from table (3) that the participants varied in response to the treatment they received form the dentists when they have an infection. Over half the dentists $(55.6 \%)$ treat the infected patient in the clinic with maximum level of protection, 17.1 of dentists treated them with the acceptable minimum level of prevention, $14.7 \%$ of dentists transferred them to clinic of specialists for these cases, while $7.1 \%$ refused treatment and 5.6\% has never encountered such cases. 
Table 4. Preparation phase before treating the patient.

\begin{tabular}{|c|c|c|c|c|c|c|c|c|c|}
\hline Statement & & No & Rare & Sometime & Often & Always & Total & Mean & SD \\
\hline \multirow{2}{*}{ Washing hands thoroughly with soap before wearing gloves } & $\mathrm{F}$ & 8 & 10 & 35 & 72 & 127 & 252 & \multirow{2}{*}{4.19} & \multirow{2}{*}{1.027} \\
\hline & $\%$ & 3.2 & 4.0 & 13.9 & 28.6 & 50.4 & 100 & & \\
\hline \multirow{2}{*}{ Water allows to flow out of the air and water syringe } & $\mathrm{F}$ & 16 & 11 & 29 & 68 & 128 & 252 & \multirow{2}{*}{4.12} & \multirow{2}{*}{1.167} \\
\hline & $\%$ & 6.3 & 4.4 & 11.5 & 27 & 50.8 & 100 & & \\
\hline \multirow{2}{*}{ Water allows to flow outside the hand piece } & $\mathrm{F}$ & 19 & 10 & 41 & 71 & 111 & 252 & \multirow{2}{*}{3.97} & \multirow{2}{*}{1.202} \\
\hline & $\%$ & 7.5 & 4.0 & 16.3 & 28.2 & 44.0 & 100 & & \\
\hline \multirow{2}{*}{ The handles lighting covered with plastic sheets } & $\mathrm{F}$ & 67 & 56 & 58 & 28 & 43 & 252 & \multirow{2}{*}{2.70} & \multirow{2}{*}{1.413} \\
\hline & $\%$ & 26.6 & 22.2 & 23.0 & 11.1 & 17.1 & 100 & & \\
\hline \multirow{2}{*}{ The patient is asked to use mouthwash before starting the treatment. } & $\mathrm{F}$ & 44 & 68 & 88 & 38 & 14 & 252 & \multirow{2}{*}{2.64} & \multirow{2}{*}{1.104} \\
\hline & $\%$ & 17.5 & 27.0 & 34.9 & 15.1 & 5.6 & 100 & & \\
\hline \multirow{2}{*}{ The hand cushion covered with plastic sheets } & $\mathrm{F}$ & 77 & 54 & 44 & 47 & 30 & 252 & \multirow{2}{*}{2.60} & \multirow{2}{*}{1.395} \\
\hline & $\%$ & 30.6 & 21.4 & 17.5 & 18.7 & 11.9 & 100 & & \\
\hline \multirow{2}{*}{ The head cushion covered with the plastic sheets } & $\mathrm{F}$ & 99 & 50 & 37 & 42 & 24 & 252 & \multirow{2}{*}{2.37} & \multirow{2}{*}{1.390} \\
\hline & $\%$ & 39.3 & 19.8 & 14.7 & 16.7 & 9.5 & 100 & & \\
\hline \multirow{2}{*}{$\begin{array}{l}\text { laboratory tests to make sure the patient is free of infectious diseases } \\
\text { before embarking on treatment }\end{array}$} & $\mathrm{F}$ & 77 & 88 & 60 & 9 & 18 & 252 & \multirow{2}{*}{2.22} & \multirow{2}{*}{1.134} \\
\hline & $\%$ & 30.6 & 34.9 & 23.8 & 3.6 & 7.1 & 100 & & \\
\hline Mean average & & & & & & & & 3.10 & \\
\hline
\end{tabular}

We can see from table (4) that the participants vary in response to the role of the dentists during preparation phase control with the mean range from $\mu=4.19$ to $\mu=2.22$ ranging from agreement to disagreement. The highest mean range was for hands washing thoroughly with soap before wearing gloves. On the other hand, the lowest mean was for laboratory tests to make sure the patient is free from infectious diseases before embarking on treatment.

Table 5. Stage of patient treatment.

\begin{tabular}{|c|c|c|c|c|c|c|c|c|c|}
\hline Statements & & No & Rare & Sometime & Often & Always & Total & Mean & SD \\
\hline \multirow{2}{*}{ The gloves will be changed after each patient. } & $\mathrm{F}$ & & & & 25 & 227 & 252 & \multirow{2}{*}{4.90} & \multirow{2}{*}{.300} \\
\hline & $\%$ & & & & 9.9 & 90.1 & 100 & & \\
\hline \multirow{2}{*}{ The gloves will be changed if torn } & $\mathrm{F}$ & & 5 & & 21 & 226 & 252 & \multirow{2}{*}{4.86} & \multirow{2}{*}{.492} \\
\hline & $\%$ & & 2.0 & & 8.3 & 89.7 & 100 & & \\
\hline \multirow{2}{*}{ Wearing sterile gloves } & $\mathrm{F}$ & 2 & 13 & & 31 & 206 & 252 & \multirow{2}{*}{4.69} & \multirow{2}{*}{.788} \\
\hline & $\%$ & .8 & 5.2 & & 12.3 & 81.7 & 100 & & \\
\hline \multirow{2}{*}{$\begin{array}{l}\text { The forceps will be used to pick up items that have not been prepared in } \\
\text { advance, such as cotton and other }\end{array}$} & $\mathrm{F}$ & 5 & 15 & 27 & 52 & 153 & 252 & \multirow{2}{*}{4.32} & \multirow{2}{*}{1.016} \\
\hline & $\%$ & 2 & 6 & 10.7 & 20.6 & 60.7 & 100 & & \\
\hline \multirow{2}{*}{$\begin{array}{l}\text { A sufficient number of tools and materials will be provided for } \\
\text { processing }\end{array}$} & $\mathrm{F}$ & 7 & 15 & 26 & 58 & 146 & 252 & \multirow{2}{*}{4.27} & \multirow{2}{*}{1.049} \\
\hline & $\%$ & 2.8 & 6 & 10.3 & 23.0 & 57.9 & 100 & & \\
\hline \multirow{2}{*}{ The medical protective masks will be changed when exposed to moisten } & $\mathrm{F}$ & 18 & 5 & 37 & 24 & 168 & 252 & \multirow{2}{*}{4.27} & \multirow{2}{*}{1.213} \\
\hline & $\%$ & 7.1 & 2.0 & 14.7 & 9.5 & 66.7 & 100 & & \\
\hline \multirow{2}{*}{ A good system for ventilation will be provided inside the clinic } & $\mathrm{F}$ & 7 & 18 & 20 & 78 & 129 & 252 & \multirow{2}{*}{4.21} & \multirow{2}{*}{1.043} \\
\hline & $\%$ & 2.8 & 7.1 & 7.9 & 31.0 & 51.2 & 100 & & \\
\hline \multirow{2}{*}{$\begin{array}{l}\text { Getting rid of non-used material to treat the patient, such as cotton and } \\
\text { gauze }\end{array}$} & $\mathrm{F}$ & 13 & 22 & 28 & 26 & 163 & 252 & \multirow{2}{*}{4.21} & \multirow{2}{*}{1.239} \\
\hline & $\%$ & 5.2 & 8.7 & 11.1 & 10.3 & 64.7 & 100 & & \\
\hline \multirow{2}{*}{ The protective medical masks will be worn } & $\mathrm{F}$ & 19 & 13 & 45 & 42 & 133 & 252 & \multirow{2}{*}{4.02} & \multirow{2}{*}{1.264} \\
\hline & $\%$ & 7.5 & 5.2 & 17.9 & 16.7 & 52.8 & 100 & & \\
\hline \multirow{2}{*}{$\begin{array}{l}\text { When taking a radiological film are sterilized tools used for determining } \\
\text { the direction of the film after each patient }\end{array}$} & $\mathrm{F}$ & 27 & 13 & 49 & 42 & 121 & 252 & \multirow{2}{*}{3.86} & 1354 \\
\hline & $\%$ & 10.7 & 5.2 & 19.4 & 16.7 & 48.0 & 100 & & 1.304 \\
\hline The nrotective medical masks will he chanoed after each natient & $\mathrm{F}$ & 28 & 10 & 38 & 73 & 103 & 252 & 385 & 1304 \\
\hline 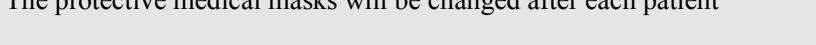 & $\%$ & 11.1 & 4.0 & 15.1 & 29.0 & 40.9 & 100 & & \\
\hline & F & 18 & 20 & 59 & 67 & 88 & 252 & & \\
\hline The goggles will be disinfected after each patient & $\%$ & 7.1 & 7.9 & 23.4 & 26.6 & 34.9 & 100 & 3.74 & 1.218 \\
\hline Use of tools intended for one-time use & $\mathrm{F}$ & 29 & 39 & 33 & 31 & 120 & 252 & 3.69 & 1.475 \\
\hline Use or toors intentied for one-time use & $\%$ & 11.5 & 15.5 & 13.1 & 12.3 & 47.6 & 100 & & \\
\hline Wear nrotective olasses for vour eves & $\mathrm{F}$ & 18 & 5 & 37 & 24 & 168 & 252 & 354 & 1101 \\
\hline & $\%$ & 7.1 & 2.0 & 14.7 & 9.5 & 66.7 & 100 & 0.04 & \\
\hline Mean average & & & & & & & & 3.69 & \\
\hline
\end{tabular}

We can see from table (5) that the participants varied in response to the role of the dentists during patient treatment phase control with the mean range from $\mu=4.90$ to $\mu=3.54$ ranging from agreement to strongly agreement. The highest 
mean range was for "the gloves will be changed after each patient". On the other hand, the lowest mean was "wear

protective glasses for your eyes".

Table 6. Post patient treatment phase.

\begin{tabular}{|c|c|c|c|c|c|c|c|c|c|}
\hline Statements & & No & Rare & Sometime & Often & Always & Total & Mean & SD \\
\hline \multirow{2}{*}{ Wash your hands thoroughly with soap after taking off gloves } & $\mathrm{F}$ & 5 & & 12 & 42 & 193 & 252 & \multirow{2}{*}{4.66} & \multirow{2}{*}{.749} \\
\hline & $\%$ & 2.0 & & 4.8 & 16.7 & 76.6 & 100 & & \\
\hline \multirow{2}{*}{ Follow-up cleaning of tools before embarking sterilization } & $\mathrm{F}$ & 11 & 8 & 5 & 37 & 191 & 252 & \multirow{2}{*}{4.54} & \multirow{2}{*}{1.003} \\
\hline & $\%$ & 4.4 & 3.2 & 2.0 & 14.7 & 75.8 & 100 & & \\
\hline \multirow{2}{*}{$\begin{array}{l}\text { The external surfaces inside the clinic, which is not covered will be } \\
\text { followed up with cleaning and disinfection, }\end{array}$} & $\mathrm{F}$ & 8 & 16 & 15 & 50 & 163 & 252 & \multirow{2}{*}{4.37} & \multirow{2}{*}{1.057} \\
\hline & $\%$ & 3.2 & 6.3 & 6.0 & 19.8 & 64.7 & 100 & & \\
\hline \multirow{2}{*}{ All adhesives Plastic covers will be changed } & $\mathrm{F}$ & 32 & 6 & 19 & 58 & 137 & 252 & \multirow{2}{*}{4.04} & \multirow{2}{*}{1.365} \\
\hline & $\%$ & 12.7 & 2.4 & 7.5 & 23 & 54.4 & 100 & & \\
\hline \multirow{2}{*}{ Monitor sterilization by recording the temperature and pressure } & $\mathrm{F}$ & 33 & 20 & 25 & 37 & 137 & 252 & \multirow{2}{*}{3.89} & \multirow{2}{*}{1.461} \\
\hline & $\%$ & 13.1 & 7.9 & 9.9 & 14.7 & 54.4 & 100 & & \\
\hline \multirow{2}{*}{ Follow-up of packaging all materials required to be sterilized } & $\mathrm{F}$ & 34 & 18 & 30 & 39 & 131 & 252 & \multirow[b]{2}{*}{3.85} & \multirow[b]{2}{*}{1.458} \\
\hline & $\%$ & 13.5 & 7.1 & 11.9 & 15.5 & 52.0 & 100 & & \\
\hline \multirow{2}{*}{$\begin{array}{l}\text { Follow-up examination sterilization devices to ensure their } \\
\text { effectiveness }\end{array}$} & $\mathrm{F}$ & 87 & 45 & 20 & 29 & 71 & 252 & \multirow{2}{*}{2.81} & \multirow{2}{*}{1.666} \\
\hline & $\%$ & 34.5 & 17.9 & 7.9 & 11.5 & 28.2 & 100 & & \\
\hline Mean average & & & & & & & & & \\
\hline
\end{tabular}

We can see from table (6) that the participants varied in response to the role of the dentists post patient treatment phase control with the mean range from $\mu=4.66$ to $\mu=2.81$ ranging from strongly agreement to disagreement. The highest mean range was for "wash your hands thoroughly with soap after takeoff gloves". On the other hand, the lowest mean was "follow-up examination of the biology of sterilization devices to ensure their effectiveness".

Table 7. Data of medical waste management.

\begin{tabular}{|c|c|c|c|c|c|c|c|c|c|}
\hline Statements & & No & Rare & Sometime & Often & Always & Total & Mean & SD \\
\hline \multirow{2}{*}{ Putting a hazardous medical waste in a thick containers } & $\mathrm{F}$ & 98 & 45 & 23 & 19 & 67 & 252 & \multirow{2}{*}{2.65} & \multirow{2}{*}{1.662} \\
\hline & $\%$ & 38.9 & 17.9 & 9.1 & 7.5 & 26.6 & 100 & & \\
\hline \multirow{2}{*}{ Putting sharps waste and lancets in a puncture-resistant containers } & $\mathrm{F}$ & 100 & 36 & 33 & 22 & 61 & 252 & \multirow{2}{*}{2.63} & \multirow{2}{*}{1.632} \\
\hline & $\%$ & 39.7 & 14.3 & 13.1 & 8.7 & 24.2 & 100 & & \\
\hline \multirow{2}{*}{ Use a dedicated container for each type of medical waste } & $\mathrm{F}$ & 119 & 31 & 18 & 25 & 59 & 252 & \multirow{2}{*}{2.50} & \multirow{2}{*}{1.676} \\
\hline & $\%$ & 47.2 & 12.3 & 7.1 & 9.9 & 23.4 & 100 & & \\
\hline Provide safety tools for workers with medical waste & $\mathrm{F}$ & 109 & 60 & 34 & 30 & 19 & 252 & 2.17 & 1.304 \\
\hline \multirow{2}{*}{$\begin{array}{l}\text { Putting a chemical waste as amalgam in strong container do not interact } \\
\text { with the chemicals to be disposed of } \\
\text { Mean average }\end{array}$} & $\mathrm{F}$ & 157 & 22 & 25 & 28 & 20 & 252 & \multirow{2}{*}{1.94} & \multirow{2}{*}{1.373} \\
\hline & $\%$ & 62.3 & 8.7 & 9.9 & 11.1 & 7.9 & 100 & & \\
\hline
\end{tabular}

We can see from table (7) that the participants varied in response to the role of the dentists in medical waste management control with the mean range from $\mu=2.65$ to $\mu=$ 1.94 ranging from neutral to disagreement. The highest mean range was for "putting a hazardous medical waste in thick containers". On the other hand, the lowest mean was "putting a chemical waste as amalgam in strong containers does not interact with the chemicals to be disposed of'.

Table 8. Type of qualified nursing staff inside the dental clinics.

\begin{tabular}{lllll}
\hline & Frequency & Percent & Valid Percent & Cumulative Percent \\
\hline No qualification & 209 & 82.9 & 82.9 & 82.9 \\
Training courses & 20 & 7.9 & 7.9 & 90.9 \\
Diploma & 23 & 9.1 & 9.1 & 100.0 \\
Total & 252 & 100.0 & 100.0 & \\
\hline
\end{tabular}

We can see from table (8) that the participants varied in response to qualification of the nursing staff $83.9 \%$ have only

experience (without qualification), 9.1\% diploma in nursing science and $7.9 \%$ having training courses.

Table 9. Nursing staff training.

\begin{tabular}{lll}
\hline Statements & Frequency(yes) & Percent \\
\hline Is there a sufficient number of nursing staff within dental clinics? & 42.9 \\
Are there training courses for the staff of the nursing within the dental clinics? & 108 & 72 \\
Is there a familiarity with infection control procedures by the nursing staff within the dental clinics & 28.6 & 136 \\
*Does the nursing staff apply these measures? & 54.0 & 115 \\
\hline
\end{tabular}


We can see from table (9) that the participants varied in response to role of the nursing staff to training. About 108 $(42.9 \%)$ stated that there is sufficient number of nursing staff within dental clinics. $72(28.6 \%)$ reported "there are training courses for the staff of the nursing within the dental clinics.
$136(54 \%)$ reported there is familiarity with infection control procedures by the nursing staff within the dental clinics. 115 $(84.6 \%)$ demonstrated that nursing staff apply these measures (from the total of 136).

Table 10. Role of the patient.

\begin{tabular}{|c|c|c|c|c|c|c|c|c|c|}
\hline Statements & & $\begin{array}{l}\text { Strongly } \\
\text { Disagree }\end{array}$ & Disagree & Neutral & Agree & $\begin{array}{l}\text { Strongly } \\
\text { Agree }\end{array}$ & Total & Mean & SD \\
\hline \multirow{2}{*}{$\begin{array}{l}\text { We do not give instructions(guidelines) for patient on the } \\
\text { prevention of infection }\end{array}$} & $\mathrm{F}$ & 13 & 30 & 48 & 67 & 94 & 252 & \multirow{2}{*}{3.79} & \multirow{2}{*}{1.211} \\
\hline & $\%$ & 5.2 & 11.9 & 19.0 & 26.6 & 37.3 & 100.0 & & \\
\hline \multirow{2}{*}{$\begin{array}{l}\text { The patient has an awareness regarding modes of infection } \\
\text { transmission }\end{array}$} & $\mathrm{F}$ & 19 & 73 & 54 & 56 & 50 & 252 & \multirow{2}{*}{3.18} & \multirow{2}{*}{1.258} \\
\hline & $\%$ & 7.5 & 29.0 & 21.4 & 22.2 & 19.8 & 100.0 & & \\
\hline The patient with an infectious disease discloses about his/her & $\mathrm{F}$ & 32 & 64 & 63 & 37 & 56 & 252 & \multirow{2}{*}{3.08} & \multirow{2}{*}{1.341} \\
\hline health before proceeding with treatment & $\%$ & 12.7 & 25.4 & 25 & 14.7 & 22.2 & 100 & & \\
\hline
\end{tabular}

We can see from table (10) that the participants varied in response to the role of patients in dental infection control with the mean range from $\mu=3.79$ to $\mu=3.08$ ranging from neutral to agreement. The highest mean range was for item "we do instructions (guidelines) for patients on the prevention of infection". Conversely, the lowest mean was for "the patient with an infectious disease discloses about his health before proceeding with treatment".

Table 11. Level of satisfaction with the infection control in dental clinics.

\begin{tabular}{lllll}
\hline & Frequency & Percent & Valid Percent & Cumulative Percent \\
\hline Dissatisfied & 158 & 62.7 & 62.7 & 62.7 \\
Neutral & 45 & 17.9 & 17.9 & 80.6 \\
Satisfied & 49 & 19.4 & 19.4 & 100.0 \\
Total & 252 & 100.0 & 100.0 & \\
\hline
\end{tabular}

We can see from table (11) that the participants varied in response to level of the satisfaction regarding the dental infection control. $62.7 \%$ were dissatisfied, $19.4 \%$ were satisfied, while $18 \%$ were natural. They justified the causes behind this dissatisfaction as it follows:

1. The absence of control and supervision from the Ministry of Health and health offices in the city and absence of special infection control department (32\%);

2. Lack of work or special educational sessions to guide infection control as well as lack of specialists in the field of infection control $(22 \%)$;

3. Lack of knowledge and familiarity with infection control as dental clinics and lack of desire and attention by doctors and nursing staff (double ethical scruples) $(18 \%)$;

4. Lack of the necessary capabilities (tools and devices) (16\%);

5. Patient disclosure for any infectious diseases because of fear of not getting acceptance for treatment in clinics $(6 \%)$

6. Laboratory tests did not perform for health workers $(3 \%)$

7. Absence of specific patient clinic records (2\%); and

8. Received large number of patients in some clinics and hospitals (1\%).

\section{Discussion}

This study was undertaken to assess infection control in the administrators' procedures in dental practices, in the medical waste management, in the nursing staff knowledge and practices and from the patients' perceptive.

We will start with the role of administrators in dental infection control. It was weak regarding infection control in distribution of the infection control guidelines for workers, adopting the guidelines for infection control, work sessions (workshops) for improving the knowledge among the health workers, follow-up records of patients with infectious diseases, inspection campaigns and constant monitoring, consultation, communication between the departments and providing feedback for doctors and physicians about any deficiencies in the application of infection control procedures.(Al-Ahmdi and Amarapathy stressed on the role of the administration on the communication and feedback in addition to applying the non-punitive response to improve the infection control management $[1,2]$.

The participants also varied in response to treating infected patients $55.6 \%$ treat the infected patient in the clinic with maximum high level of protection as compared to $17.1 \%$ of participants treating in the clinic with the acceptable minimum level of prevention. $14.7 \%$ of participants transfer the patients to clinic specialist, $7.1 \%$ refuse treatment, and finally $5.6 \%$ has never encountered such case. The variation in response to treat patients with the infectious disease reflect the variation in knowledge and practices among the dentists due to absence of the clinical practice guidelines that guide the dentists to deal with the infectious disease.

In the regard to the role of the dentists, our study showed 
that the dentist comply with the hands washing thoroughly with soap before wearing gloves, allow water to flow out of the air and water syringe and headpiece, but not utilize the full range of procedures like cover the dental chairs with the plastic barriers, ask the patient to use the mouth wash and work of laboratory tests to make sure the patient is free of infectious diseases before embarking on treatment. Such results are in agreement with the previously reported by [15] and [7] in the vital role of dentist in infection and health care matters.

With the regards to the dentists' post patient treatment phase, the result contrasts a previous study conducted by [24] who reported lack of dentists' knowledge regarding the hand washing hygiene. Nevertheless, the lowest mean was "follow-up examination of the biology of sterilization devices to ensure their effectiveness". This result is in agreement with the previously reported studies by [22] and [6] who stated that dentists didn't follow the procedures that aim to eliminate the microorganism.

As for medical waste management there is a shortage in practical dealing with the medical waste in the following procedures: lack in putting a hazardous medical waste in a thick containers, lack in putting sharps waste and lancets in a puncture-resistant containers, didn't segregate the medical waste, lack to provide safety tools for workers with medical waste and lack in putting a chemical waste as amalgam in strong container do not interact with the chemicals to be disposed of. This result is in agreement with study of [3] which reported that $32 \%$ of dentists did not dispose the materials and the sharp instruments properly.

The qualification of the nursing staff varied from $83.9 \%$ having only experience (without qualification), 9.1\% diploma in nursing science, to $7.9 \%$ having training courses. So most of the assistant staff in the dental clinics were without qualification degree, reflecting the lack of solid knowledge of assistant staff regarding infection control.

Additionally, our survey showed that the patients with an infectious disease don't usually disclose about his/her health before proceeding with treatment). We can see the problem is with the patients who do not disclose his/her health specially if $s /$ he has infectious disease, but the dentist understands that from the patient's behavior. Having this in mind, they refuse treatment from the dentists, due to a lack of dentists' knowledge regarding the infectious disease they have.

Finally, the participants varied in responding to level of the satisfaction regarding the dental infection control. $62.7 \%$ were dissatisfied, $19.4 \%$ were satisfied, while $18 \%$ neutral.

\section{Conclusions}

The current survey-study aimed at assessing and identifying infection control practical procedures from the dentists' perspective. Toward this end a self-designed questionnaire was developed to achieve the objectives of this study, and distributed to all dentists (government, educational and private and dental centers). The sample consisted of 252 dentists from different hospitals in the Republic of Yemen, mainly Ibb city, selected randomly.
The main results of the study were: 1) the participating dentists agreed to the idea of ineffective role of the administration regarding infection control, 2) the participants' perceptions varied in responding to the role of the dentists during the preparation stage and post treatment stage, but generally agreed to the proposed procedures in treatment phase practices, 3) there was a shortage in practical dealing with medical waste management regarding the segregation and use of thick good containers for the wastes, 4) there was a clear shortage in the qualification and training of the nursing staff, and 5) according to the results of this study, the biggest problem was with the patients who have infectious diseases and did not reveal their health status to the dentists. Nearly $62.7 \%$ of the dentists were dissatisfied with the current infection control management also dissatisfied with the role administration of the hospital and the Ministry of the Health regarding practical guidance, training and supervision.

\section{Recommendations}

To the Ministry of Health in the Republic of Yemen:

1. Creating a particular infection control department in all health offices in the cities;

2. Adopting guidelines and increasing the number of specialists in the field of infection control;

3. Providing formal and obligatory training in infection control program for all dentists and nurses with the mandatory attendance to improve their skills toward the implementation of effective control measures;

4. Disseminating the Infection control guidelines manual for dental practice that has already been developed by the Ministry of Health and that should be available to the dental clinics; and

5. Increasing the number of scholarships in the specialty of infection control.

To health offices and hospital administration

1. Offering $\mathrm{HBV}$ immunization and post immunization test(s) for all health workers in dental clinics;

2. Developing knowledge of doctors with the regard to medical waste and how to handle them; dentists must emphasis on the preparation phase and the post treatment phase;

3. The administration of the hospitals and dental centers must develop patient records;

4. Paying attention to training, consulting, workshops, and medical work for patients and providing the necessary materials, tools and supplements to the clinics to avoid reuse of the same materials;

5. Increasing the number of nursing staff in the clinics; and

6. Performing (a) regular check-up(s) for health workers to make sure they are free from any infectious diseases.

To patients:

1. S/he must be willing to openly disclose his/her current health status and must encourage doing that to avoid transmitting the infection to the staff and other patients.

General recommendation: 
For future studies, increasing the sample size and the inclusion of other cities to evaluate infection control practice would certainly allow greater generalizability of the results and lead to more solid findings.

\section{References}

[1] Al-Ahmadi, T. A. (2009). Measuring Patient Safety Culture in Riyadh's Hospitals: A Comparison between Public and Private Hospitals. The Journal Of The Egyptian Public Health Association, 84(5-6), 479-500.

[2] Amarapathy, M.(2013) Factors Affecting Patient Safety Culture In A Tertiary Care Hospital In Sri Lanka, International Journal Of Scientific \& Technology Research Volume 2, Issue 3, ISSN 2277-8616.

[3] Bansal, M., Vashisth, S., \& Gupta, N. (2013). Knowledge, awareness and practices of dental care waste management among private dental practitioners in Tricity (Chandigarh, Panchkula and Mohali). Journal of International Society Of Preventive \& Community Dentistry, 3(2), 72.

[4] Barghout, N., Al Habashneh, R., Ryalat, S. T., Asa'ad, F. A., \& Marashdeh, M. (2012). Patients' Perception of Cross-infection Prevention in Dentistry in Jordan. Oral Health \& Preventive Dentistry, 10(1), 9.

[5] Baseer, M. A. (2013). Knowledge and Attitude of Dental Patients towards Cross-Infection Control Measures. Indian Journal Of Dental Education, 6(4), 179

[6] Batool, A., Khan Sherwani, M., Bano, K., \& Aasim, M. (2012). Knowledge, Attitude and Practices of Dentists about Hepatitis $\mathrm{B}$ and $\mathrm{C}$ Infection in Lahore. Pakistan Journal Of Medical Research, 51(3), 93-96.

[7] Budnyak, M. A., Gurevich, K. G., Fabrikant, K., Miller, K., \& Puttaiah, R. (2012). Dental Infection Control and Occupational Safety in the Russian Federation. Journal of Contemporary Dental Practice, 13(5), 703.

[8] Cleveland, J. L., Foster, M., Barker, L., Gordon Brown, G. G., Lenfestey, N., Lux, L., \& Bonito, A. J. (2012). Advancing infection control in dental care settings. Journal of The American Dental Association (JADA), 143(10), 1127.

[9] Francisco, E. M., Johnson, T. L., Freudenthal, J. J., \& Louis, G. (2013). Dental Hygienists' Knowledge, Attitudes and Practice Behaviors Regarding Caries Risk Assessment and Management. Journal of Dental Hygiene, 87(6), 353-361.

[10] Garland, K. V. (2013). A Survey of United States Dental Hygienists' Knowledge, Attitudes, and Practices with Infection Control Guidelines. Journal of Dental Hygiene, 87(3), 140-151.

[11] Ghasemi, H., Bayat, F., Hooshmand, B., \& Maleki, Z. (2011). Determinants of Iranian dentists' behavior regarding infection control. International Dental Journal, 61(2), 85-89.

[12] Harvey, L. (2009). Risk management and patient safety: improving patient outcomes. Access, 23(2), 17-19.

[13] Khan, A., Javed, O., Khan, M., Mehboob, B., \& Baig, S. (2012). Cross infection control. Pakistan Oral \& Dental Journal, 32(1), 31 .
[14] Mahboobi, N., Porter, S. R., Karayiannis, P., \& Alavian, S. (2013). Dental treatment as a risk factor for hepatitis B and C viral infection. A review of the recent literature. Journal of Gastrointestinal And Liver Diseases:, 22(1), 79-86.

[15] McCarthy, G. M., Koval, J. J., John, M. A., \& MacDonald, J. K. (1999). Infection control practices across Canada: do dentists follow the recommendations. Journal (Canadian Dental Association), 65(9), 506-511.

[16] Nabizadeh, R., Faraji, H., \& Mohammadi, A. A. (2014). Solid Waste Production and Management in Dental Clinics in Gorgan, Northern Iran. International Journal Of Occupational \& Environmental Medicine, 5(4), 216-221.

[17] November-Rider, D., Bray, K. K., Eklund, K. J., Williams, K. B., \& Mitchell, T. V. (2012). Massachusetts Dental Public Health Program Directors Practice Behaviors and Perceptions Of Infection Control. Journal Of Dental Hygiene, 86(3), 248255

[18] Osazuwa-Peters, N. N., Azodo, C. C., Ehizele, A. O., \& Obuekwe, O. N. (2012). Gender differences in characteristics, occupational exposure, and infection control practices among dental professionals in Edo State, Nigeria. Southern African Journal of Epidemiology \& Infection, 27(2), 61.

[19] Rudraswamy, S., Sampath, N., \& Doggalli, N. (2012). Staff's attitude regarding hospital waste management in the dental college hospitals of Bangalore city, India. Indian Journal of Occupational \& Environmental Medicine, 16(2), 75-78.

[20] Singh, B., Khan, S. A., Agrawal, N., Siddharth, R., \& Kumar, L. (2012). Current biomedical waste management practices and cross-infection control procedures of dentists in India. International Dental Journal, 62(3), 111.

[21] Smith, A. J., Wilson, S. L., Read, S., Welsh, J., Gammie, E., Szuster, J., \& ... Binnie, V. (2014). Patients' perception of infection prevention in dental practice. American Journal of Infection Control, 42(3), 337-339.

[22] Szymańska, J., \& Sitkowska, J. (2013). Evaluation of activities aimed at preventing microbiological risks in dental practice. Medycyna Pracy, 64(1), 11-17.

[23] Vázquez-Mayoral, E., Sánchez-Pérez, L., Olguín-Barreto, Y., \& Acosta-Gío, A. (2009). Dental school deans' and dentists' perceptions of infection control and HIV/AIDS patient care: a challenge for dental education in Mexico. AIDS Patient Care \& Stds, 23(7), 557-562.

[24] Vega, O. G., Janus, C., \& Laskin, D. M. (2012). Handwashing knowledge and practices among dentists and dental specialists. Quintessence International, 43(5), 429.

[25] Weheida, Soheir(2008).Infection control practices in dental clinics- Jul-Ago; 60(4):277-80.

[26] Wijk, P. L., Meiberg, A. E., Bruers, J. M., Groenewold, M. H., Raalten, A. L., Dam, B. M., \& Schneeberger, P. M. (2012). The risk of blood exposure incidents in dental practices in the Netherlands. Community Dentistry \& Oral Epidemiology, 40(6), 567.

[27] Yamalik, N., \& Perea Pérez, B. (2012). Patient safety and dentistry: what do we need to know Fundamentals of patient safety, the safety culture and implementation of patient safety measures in dental practice. International Dental Journal, 62(4), 189-196. 